\title{
Association of triple positivity with prognostic parameters and overall survival in a population-based study of 6,122 HER2-positive breast cancer patients: analysis of real-world clinical practice based on a research database
}

\author{
I. KOLAROVA ${ }^{1,2}$, J. VANASEK ${ }^{2,3,4}$, M. DOLEZEL ${ }^{5,6,7}$, J. STUK ${ }^{4}$, A. HLAVKA ${ }^{3,4}$, L. DUSEK $^{8}$, B. MELICHAR ${ }^{1,5,7,9}$, T. BUCHLER ${ }^{10}$, A. RYSKA ${ }^{11}$, J. PRAUSOVA ${ }^{12}$, \\ K. PETRAKOVA ${ }^{13}$, P. TESAROVA ${ }^{6,14}$, J. PETERA ${ }^{1,9}$, M. VOSMIK ${ }^{1,9}$, K. HORACKOVA ${ }^{2}$, J. JARKOVSKY ${ }^{8, *}$
}

\begin{abstract}
${ }^{1}$ Department of Oncology and Radiotherapy, University Hospital Hradec Kralove, Hradec Kralove, Czech Republic; ${ }^{2}$ Faculty of Health Studies, University of Pardubice, Pardubice, Czech Republic; ${ }^{3}$ Department of Medical and Radiation Oncology, Pardubice Hospital, Pardubice, Czech Republic; ${ }^{4}$ Radiology Centre Multiscan, Ltd., Pardubice, Czech Republic; ${ }^{5}$ Department of Oncology, Palacky University Medical School and Teaching Hospital, Olomouc, Czech Republic; ${ }^{6}$ First Faculty of Medicine, Charles University, Prague, Czech Republic; ${ }^{7}$ Faculty of Medicine and Dentistry, Palacky University Olomouc, Olomouc, Czech Republic; ${ }^{8}$ Institute of Biostatistics and Analyses, Faculty of Medicine, Masaryk University, Brno, Czech Republic; ${ }^{9}$ Faculty of Medicine in Hradec Kralove, Charles University, Hradec Kralove, Czech Republic; ${ }^{10}$ Department of Oncology, First Faculty of Medicine, Charles University and Thomayer Hospital, Prague, Czech Republic; ${ }^{11}$ The Fingerland Department of Pathology, Faculty of Medicine, Charles University and University Hospital Hradec Kralove, Czech Republic; ${ }^{2}$ Department of Oncology, University Hospital in Motol, Prague, Czech Republic; ${ }^{13}$ Department of Comprehensive Cancer Care, Masaryk Memorial Cancer Institute, Brno, Czech Republic; ${ }^{14}$ Department of Oncology, General University Hospital in Prague, Prague, Czech Republic
\end{abstract}

${ }^{*}$ Correspondence: jarkovsky@iba.muni.cz

Received October 23, 2019 / Accepted February 19, 2020

\begin{abstract}
Triple-positive breast cancer (TPBC), i.e. HER2-positive (HER2+) and hormone receptors-positive breast cancer, is a specific subgroup of breast cancers. TPBC biology is characterized by strong mutual interactions between signaling pathways stimulated by estrogens and HER 2 amplification. The present study aims to carry out a population-based analysis of treatment outcomes in a cohort of hormone receptor (HR) positive and negative breast cancer patients who were treated with anti-HER2 therapy in the Czech Republic. The BREAST research database was used as the data source for this retrospective analysis. The database covers approximately $95 \%$ of breast cancer patients treated with targeted therapies in the Czech Republic. The analysis included 6,122 HER2-positive patients. The patients were divided into two groups, based on estrogen receptor (ER) or progesterone receptor (PR) positivity: hormone receptor negative (HR-) patients had both ER- and PR-negative tumors $(n=2,518)$, unlike positive $(H R+)$ patients $(n=3,604)$. HR+ patients were more often diagnosed premenopausal at the time of diagnosis, presented more often at stage I or II and their tumors were less commonly poorly differentiated. The overall survival (OS) was significantly higher in subgroups of HR+ patients according to treatment setting. When evaluated by stages, significantly higher OS was observed in HR+ patients diagnosed at stages II, III, and IV and regardless of tumor grade.
\end{abstract}

Key words: breast cancer, triple positive, HER2-positive, hormone receptors, trastuzumab, overall survival

Advances in the diagnosis and adjuvant therapy have resulted in a decrease in breast cancer mortality [1-3]. Personalized therapy relies on the evaluation of clinical and pathological parameters predicting the prognosis, response to therapy and toxicity, including the patient's age, presence of comorbidities, clinical stage as well as tumor biomarkers such as the expression of hormone receptors (HR) or the human epidermal growth factor receptor 2 (HER2). These parameters routinely determine the management of newly diagnosed breast cancer cases [4].

In general, the expression of estrogen receptors (ER) and progesterone receptors (PR) is associated with better outcomes. Overall survival (OS), disease-free survival, or time to progression are positively affected by the expression of ER and PR [5-7]. However, it should be noted that although the initial relapse rate is higher in ER-negative (ER-) tumors during the first five years after diagnosis, results of long-term follow-up have shown a higher frequency of late relapses in ER-positive (ER+) tumors $[8,9]$. HER2 amplification is a biomarker of poor prognosis in patients not treated with anti-HER2 therapy [10-12].

Triple-positive breast cancer (TPBC), i.e. HER2-positive (HER2+) and HR-positive (HR+) breast tumors, has gradually emerged as a specific subgroup of breast cancers [13-15]. 
The biology of TPBC is unique due to crosstalk between HER2 and HR signaling. HR+ tumors are found in about three-quarters of breast cancer patients [16] while HER2 positivity is present in approximately $15-20 \%$ of cases. Approximately half of HER $2+$ breast cancers are therefore HR-positive as well [17].

Both preclinical and clinical data have demonstrated that ER+ and HER2+ tumors are characterized by strong interactions between signaling pathways stimulated by estrogens and HER2 receptors. This crosstalk might result in a decrease in the efficacy of hormone therapy relative to ER+ and HER2-negative tumors. Moreover, ER positivity in HER2-overexpressing tumors can lead to resistance to anti-HER2 therapies [18-22]. In addition, there is a lack of evidence for selecting an optimal treatment strategy because patients with HER2+ tumors are usually excluded from studies evaluating endocrine therapy. An optimal combination of hormone therapy, chemotherapy, and anti-HER2 therapy has yet to be found. According to the standard treatment procedure applied in the Czech Republic, TPBC is treated with combination therapy based on standard anti-HER2 therapy, hormone therapy, and cytotoxic chemotherapy as well [23-25].

The aim of the present study was to analyze prognostic factors and outcomes in a cohort of breast cancer patients treated with anti-HER2 therapy, comparing patients with positive versus negative hormone receptor status.

\section{Patients and methods}

Patients. The BREAST research database was used as the data source for this retrospective analysis. The database contains real-world epidemiological and clinical data on breast cancer patients treated with targeted therapies, including information on histology, staging, and treatment. The database is updated twice a year and covers approximately $95 \%$ of breast cancer patients treated with targeted therapies in the Czech Republic. The database has been approved by institutional boards of the participating comprehensive cancer centers.

The analysis included data of all patients who, as of January 8,2018 , had a valid record in the BREAST research database (a non-interventional post-authorization database focused on the collection of epidemiological and clinical data on breast cancer patients) and who were treated with targeted therapies in the Czech Republic since 2011. Further inclusion criteria included the availability of data on HER2, ER, and PR status, and anti-HER2 therapy. HER2 status, hormone dependence, and grades of tumors were determined in several local laboratories. The diagram of patient selection is shown in Figure 1.

The HER2 status was tested immunohistochemically in pathology laboratories where the primary histological diagnosis was made. All cases diagnosed locally were sent to one of the so-called reference laboratories (usually within comprehensive cancer centers), where the HER2 status was confirmed by CE-IVD certified immunohistochemical tests. Cases with confirmed $3+$ positivity were regarded as positive. Cases with $2+$ positivity were subsequently confirmed by in situ hybridization - of these cases, only those with amplification of the c-erb-B2 gene were regarded as HER2-positive.

The hormone receptor status was diagnosed immunohistochemically. Because the cohort was recruited over a relatively long period of time, the cut-off values for tumors to be designated as ER/PR positive have changed; therefore, different values ranging between $1 \%$ and $10 \%$ were used as threshold criteria. In other words, all cases included in the TPBC cohort showed at least $1 \%$ expression of ER or PR. The

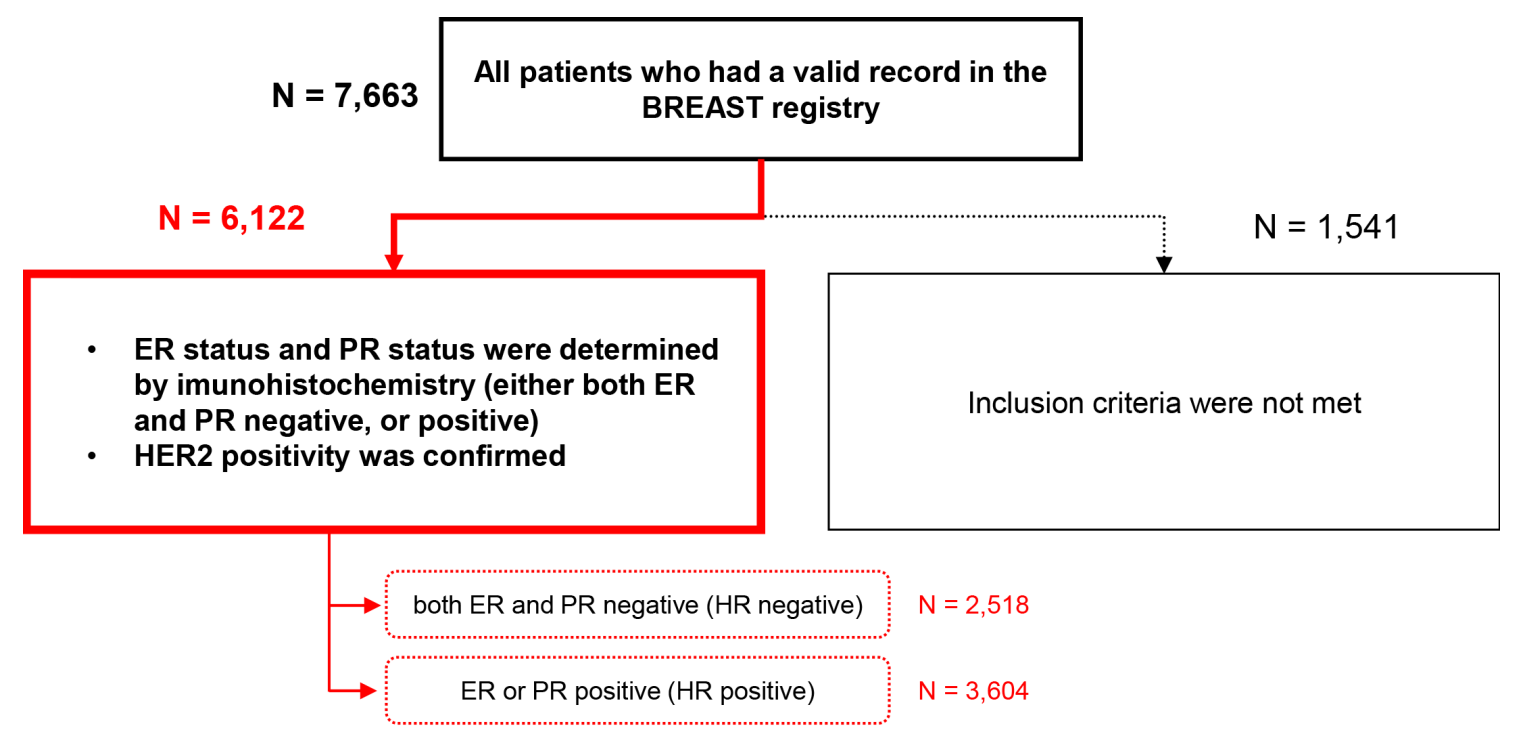

Figure 1. Analysis flowchart. 
analysis included data on patients who were administered trastuzumab in the adjuvant setting, neoadjuvant setting or to treat an advanced stage of the disease. Anti-HER2 therapy was administered to patients with HER2-positive tumors unless contraindicated.

Chemotherapy and/or radiotherapy were given to patients at the physician's discretion. Likewise, patients with hormone receptor positive tumors were or were not treated with endocrine therapy at the physician's discretion. Trastuzumab combined with chemotherapy was administered in the neoadjuvant setting and in the adjuvant setting. As for patients treated with palliative intent, trastuzumab was administered in combination with either chemotherapy or endocrine therapy. The use of oral contraceptives was strictly contraindicated.

Statistical analysis. Categorical variables were described by absolute frequencies and percentages, whereas continuous variables were described by median and range. The significance of differences between subgroups of patients was examined using Fisher's exact test for categorical variables and the Mann-Whitney U test for continuous variables.

The survival analysis was performed using the KaplanMeier method, with 95\% confidence intervals provided for all point estimates. The overall survival was calculated from the date of diagnosis to the date of death. Surviving patients were censored on the date of the last record update in the database. Survival rates of patient subgroups were compared using the log-rank test.

All statistical tests were performed at the significance level $\alpha=0.05$ using SPSS 25.0.0.1 (IBM Corporation, 2018) and R version 3.5.3 with the ggplot2 library.

\section{Results}

Patient characteristics by the presence of hormone receptors - risk factors. Overall, the analysis included data on 6,122 HER2+ patients with valid records in the BREAST research database, who were divided into two groups based on ER and PR positivity of their tumors: a) both ER and PR negative (HR negative; $n=2,518$ ), $b$ ) ER or PR positive (HR positive; $\mathrm{n}=3,604)$.

Patient characteristics are provided in Table 1. Table 2 describes the setting in which the first anti-HER2 therapy was administered.

Statistically significant differences were found in the age, menopausal status at diagnosis, histological type of the carcinoma, the grade of the primary tumor, stage at diagnosis, a performance status at the start of trastuzumab therapy. HR+ patients were more commonly premenopausal, diagnosed at stage I or II. HR- tumors were more commonly poorly differentiated. However, some of the statistically significant differences may have only a small clinical impact.

Overall survival. On the last follow-up update, a total of $\mathrm{n}=1,773(70.4 \%)$ and $\mathrm{n}=2,895$ (80.3\%) patients were alive, with a median follow-up of 3.6 years and 3.5 years in the HR-
Table 1. Basic patient characteristics.

\begin{tabular}{|c|c|c|c|}
\hline & $\begin{array}{c}\text { HR negative } \\
\quad(n=2,518)\end{array}$ & $\begin{array}{l}\text { HR positive } \\
\qquad(\mathrm{n}=3,604)\end{array}$ & p-value ${ }^{\star}$ \\
\hline \multicolumn{4}{|c|}{ Age at diagnosis (years) } \\
\hline median (range) & $57(20-88)$ & $55(23-85)$ & $<0.001$ \\
\hline \multicolumn{4}{|c|}{ Age at diagnosis, n (\%) } \\
\hline$\leq 35$ years & $135(5.4)$ & $240(6.7)$ & \multirow{5}{*}{$<0.001$} \\
\hline $35-45$ years & $328(13.0)$ & $628(17.4)$ & \\
\hline $45-60$ years & $1,057(42.0)$ & $1,416(39.3)$ & \\
\hline $60-75$ years & $901(35.8)$ & $1,206(33.5)$ & \\
\hline$\geq 75$ years & $97(3.9)$ & $114(3.2)$ & \\
\hline \multicolumn{4}{|c|}{ Menopausal status at diagnosis, n (\%) } \\
\hline premenopausal & $725(28.8)$ & $1,371(38.0)$ & \multirow{3}{*}{$<0.001$} \\
\hline postmenopausal & $1,792(71.2)$ & $2,233(62.0)$ & \\
\hline NA & 1 & 0 & \\
\hline \multicolumn{4}{|c|}{ Affected breast, n (\%) } \\
\hline right & $1,129(48.0)$ & $1,656(47.3)$ & \multirow{4}{*}{0.136} \\
\hline left & $1,188(50.5)$ & $1,761(50.3)$ & \\
\hline bilateral & $37(1.6)$ & $81(2.3)$ & \\
\hline NA & 164 & 106 & \\
\hline \multicolumn{4}{|c|}{ Histological type of the carcinoma, n (\%) } \\
\hline ductal & $2,296(91.4)$ & $3,198(89.0)$ & \multirow{5}{*}{$<0.001$} \\
\hline lobular & $59(2.3)$ & $204(5.7)$ & \\
\hline mixed & $28(1.1)$ & $66(1.8)$ & \\
\hline other & $130(5.2)$ & $124(3.5)$ & \\
\hline NA & 5 & 12 & \\
\hline \multicolumn{4}{|c|}{ Grade of the primary tumor, $\mathrm{n}(\%)$} \\
\hline 1 & $56(2.5)$ & $179(5.3)$ & \multirow{4}{*}{$<0.001$} \\
\hline 2 & $787(34.7)$ & $1,709(50.3)$ & \\
\hline 3 & $1,425(62.8)$ & $1,507(44.4)$ & \\
\hline NA & 250 & 209 & \\
\hline \multicolumn{4}{|c|}{ Stage at diagnosis, $\mathrm{n}(\%)$} \\
\hline I & $512(21.2)$ & $900(25.8)$ & \multirow{5}{*}{$<0.001$} \\
\hline II & $986(40.8)$ & $1,601(45.9)$ & \\
\hline III & $650(26.9)$ & $729(20.9)$ & \\
\hline IV & $258(10.7)$ & $247(7.1)$ & \\
\hline NA & 101 & 114 & \\
\hline \multicolumn{4}{|c|}{ Performance status (PS) at start of trastuzumab therapy, n (\%) } \\
\hline PS 0 & $1,282(72.1)$ & $2,225(77.0)$ & \multirow{4}{*}{$<0.001$} \\
\hline PS 1 & $469(26.4)$ & $625(21.6)$ & \\
\hline PS 2 or PS 3 & $27(1.5)$ & $41(1.4)$ & \\
\hline NA & 740 & 713 & \\
\hline
\end{tabular}

${ }^{*}$ Fisher's exact test or Mann-Whitney test; NA not available

Table 2. Setting of the first targeted therapy.

\begin{tabular}{lcc}
\hline $\begin{array}{l}\text { Setting of the first targeted } \\
\text { therapy } \mathbf{n}(\%)\end{array}$ & $\begin{array}{c}\text { HR negative } \\
(\mathbf{n}=\mathbf{2 , 5 1 8})\end{array}$ & $\begin{array}{c}\text { HR positive } \\
(\mathbf{n = 3}, \mathbf{6 0 4})\end{array}$ \\
\hline trastuzumab & $2,444(97.1 \%)$ & $3519(97.6 \%)$ \\
neoadjuvant & $444(17.6 \%)$ & $677(18.8 \%)$ \\
adjuvant & $1,443(57.3 \%)$ & $2314(64.2 \%)$ \\
advanced/metastatic disease & $557(22.1 \%)$ & $528(14.7 \%)$ \\
experimental treatment & $74(2.9 \%)$ & $85(2.4 \%)$ \\
\hline
\end{tabular}

Experimental treatment denotes therapy within a clinical trial that has not been adopted as the standard. 
and HR+ subgroups, respectively. One-, three-, and fiveyear OS as well as the median OS and hazard ratios within grade and stage categories are presented in Table 3. During the initial five years after diagnosis, the OS was significantly higher in HR+ patients (Figure 2).

The overall survival rate was also significantly higher in $\mathrm{HR}+$ patients stratified according to treatment setting (neoadjuvant, adjuvant, and advanced/metastatic disease, Figure 3).

Comparing subgroups of patients according to tumor stage, the results showed a higher OS in $\mathrm{HR}+$ patients diagnosed in stages II, III, and IV, but not in stage I (Figure 4).

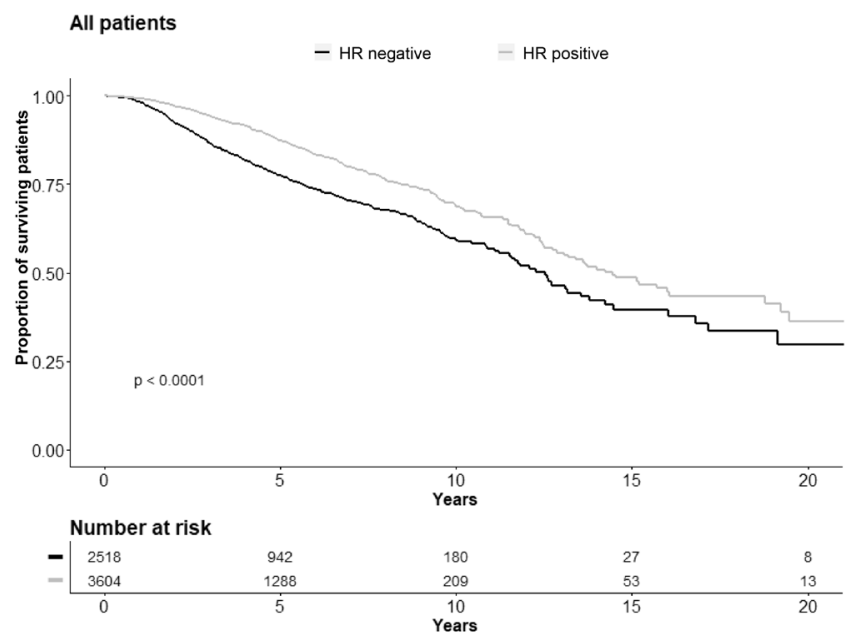

Figure 2. Overall survival.

Table 3. Overall survival (OS) from the diagnosis according to patient groups.

\begin{tabular}{|c|c|c|c|}
\hline & $\begin{array}{c}\text { HR negative } \\
(\mathrm{n}=2,518)\end{array}$ & $\begin{array}{c}\text { HR positive } \\
(\mathrm{n}=3,604)\end{array}$ & p-value ${ }^{*}$ \\
\hline Median OS (95\% CI) & $\begin{array}{l}12.5 \text { years } \\
(11.5-13.5)\end{array}$ & $\begin{array}{l}14.5 \text { years } \\
(12.7-16.2)\end{array}$ & \multirow{4}{*}{$<0.001$} \\
\hline 1-year OS (\%; 95\% CI) & $\begin{array}{c}98.2 \\
(97.7-98.8)\end{array}$ & $\begin{array}{c}99.3 \\
(99.0-99.6)\end{array}$ & \\
\hline 3-year OS (\%; 95\% CI) & $\begin{array}{c}86.6 \\
(85.1-88.2)\end{array}$ & $\begin{array}{c}94.2 \\
(93.3-95.1)\end{array}$ & \\
\hline 5-year OS (\%; 95\% CI) & $\begin{array}{c}77.4 \\
(75.3-79.4)\end{array}$ & $\begin{array}{c}87.3 \\
(85.9-88.8)\end{array}$ & \\
\hline Stratification & \multicolumn{2}{|c|}{$\begin{array}{l}\text { Hazard ratio }(95 \% \mathrm{CI}) \text { for } \mathrm{HR} \\
\text { positive vs. HR negative }\end{array}$} & p-value ${ }^{*}$ \\
\hline \multicolumn{4}{|l|}{ Grade } \\
\hline 1 & \multicolumn{2}{|c|}{$0.370(0.156 ; 0.877)$} & 0.024 \\
\hline 2 & \multicolumn{2}{|c|}{$0.503(0.401 ; 0.631)$} & $<0.001$ \\
\hline 3 & \multicolumn{2}{|c|}{$0.800(0.667 ; 0.961)$} & 0.017 \\
\hline \multicolumn{4}{|l|}{ Stage } \\
\hline $0+\mathrm{I}$ & \multicolumn{2}{|c|}{$0.711(0.463 ; 1.091)$} & 0.118 \\
\hline II & \multicolumn{2}{|c|}{$0.714(0.569 ; 0.895)$} & 0.003 \\
\hline III & \multicolumn{2}{|c|}{$0.631(0.510 ; 0.779)$} & $<0.001$ \\
\hline IV & \multicolumn{2}{|c|}{$0.614(0.474 ; 0.793)$} & $<0.001$ \\
\hline
\end{tabular}

${ }^{\star}$ Log-rank test. ${ }^{*}$ Cox proportional hazards model.
Furthermore, significantly better OS was found in patients with $\mathrm{HR}+$ tumors and tumor grades 1,2 , and 3 across the entire cohort (Figure 5).
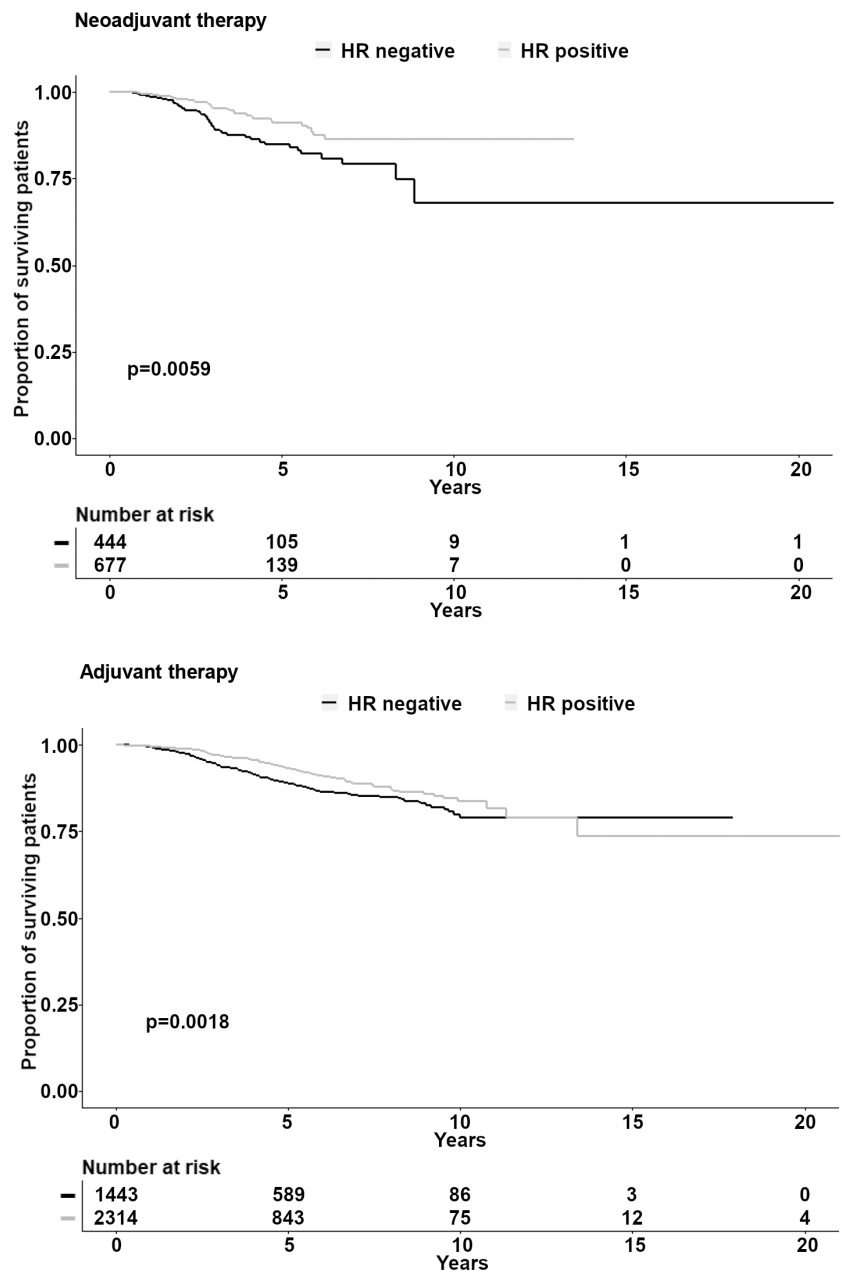

Palliation

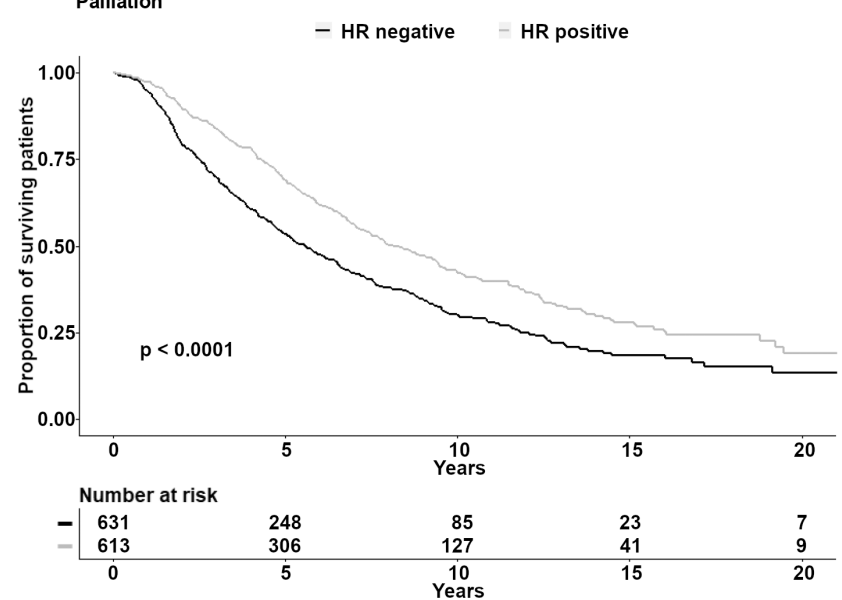

Figure 3. Overall survival according to treatment. 

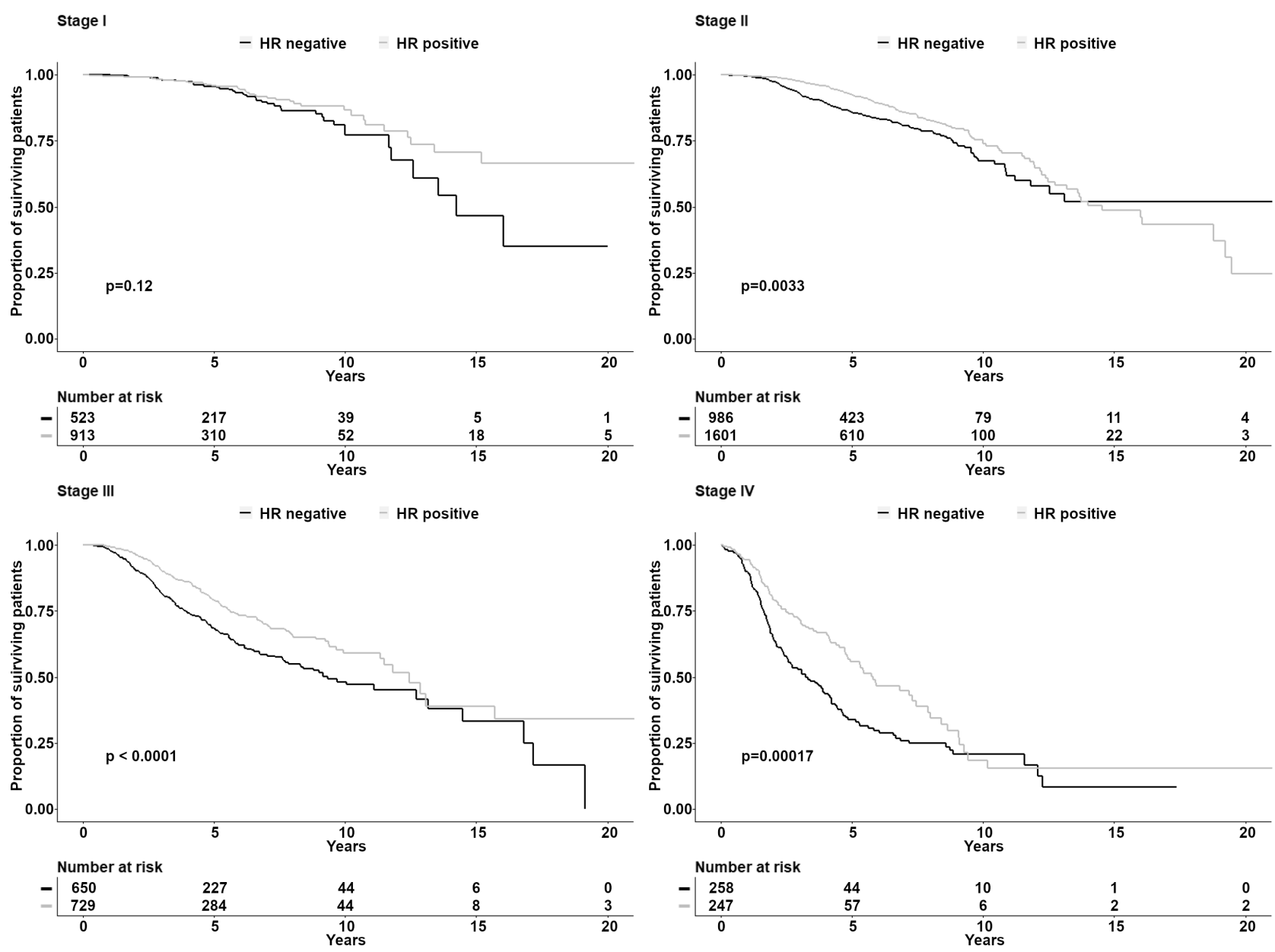

Figure 4. Overall survival according to stage.

When evaluating the effect of grade in different stages of the disease, no difference was found for grades 1,2, and 3 in $\mathrm{HR}+$ patients diagnosed at stage I (Figure 6), and a significantly higher OS was only found for grade 2 in $\mathrm{HR}+$ patients diagnosed at stage II (Figure 7). After the combination of stages III and IV, a significantly higher OS was found for grades 1, 2, and 3 in $\mathrm{HR}+$ patients (Figure 8).

\section{Discussion}

The results of the present retrospective analysis indicate a significantly higher OS in patients with HR+ tumors across the entire patient cohort. This effect, however, can only be evaluated with regard to the relatively short median followup, i.e. the first several years after the diagnosis.

We revealed the influence of HR positivity on the overall survival of patients diagnosed at stage II, III, and IV; on top of that, a higher OS was found for grade 2 in HR+ patients diagnosed at stage II. After the combination of subgroups III and IV, a higher OS was found for HR+ patients diagnosed with tumors in all grades (1,2, and 3).
According to the literature, the pattern of relapses over time is different for TPBC and HER2+/HR- tumors. In the first five years, relapses occur more frequently in HR- tumors, whereas $\mathrm{HR}+$ tumors relapse more frequently between 5 and 10 years after diagnosis [26].

A retrospective analysis of TPBC patients treated with chemotherapy alone or in combination with trastuzumab, as reported by Vici et al., demonstrated a significant effect of HR expression in the adjuvant setting [22]. Although trastuzumab was found to improve relapse-free survival (RFS) and breast-cancer specific survival in all subsets analyzed, OS differences did not reach statistical significance in the subgroup of patients with tumors containing more than $30 \%$ of hormone-dependent cells (HR $>30 \%$ ), and the lack of significant difference was even more apparent in patients with tumors characterized by HR expression in more than $50 \%$ of cells (HR $>50 \%)$. The dynamic of relapses was markedly different in the HR $>50 \%$ group, with a low risk of relapse in the first five years after diagnosis [22]. A multivariate analysis of RFS confirmed a significant interaction between ER expression and trastuzumab efficacy, with 

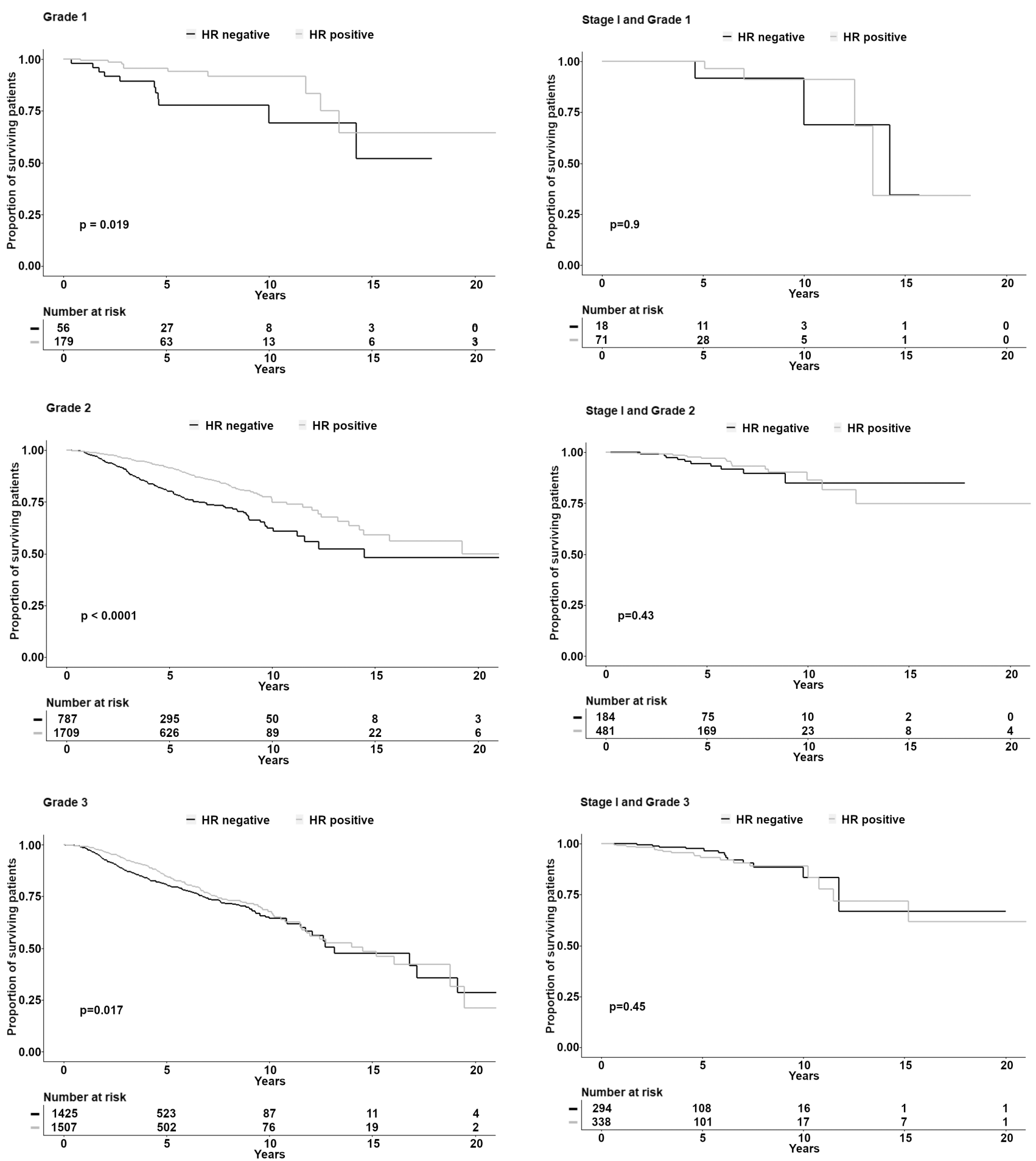

Figure 5. Overall survival according to grade.

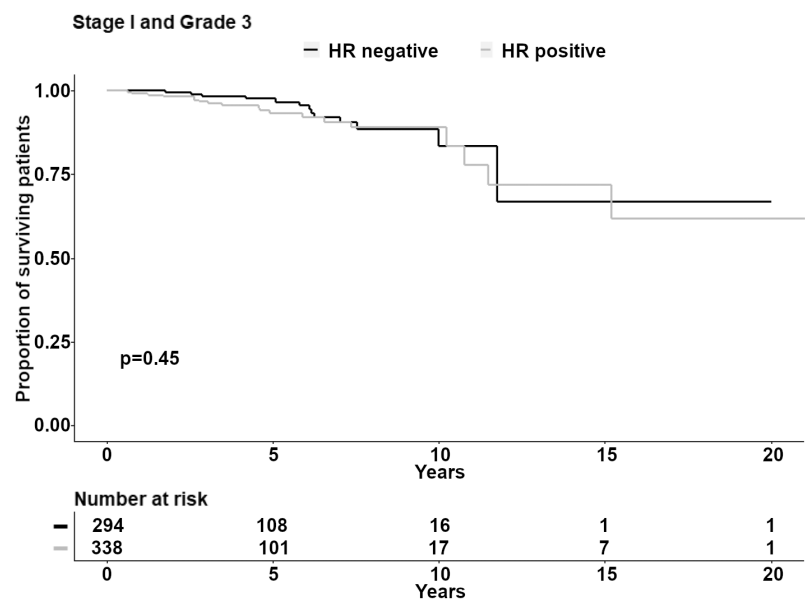

Figure 6. Overall survival according to stage I and grade 1-3.

the benefit of trastuzumab treatment confined to patients with tumors expressing ER in $\leq 50 \%$ of tumor cells [22]. Therefore, a question arises whether patients with highly hormone-dependent tumors have any meaningful benefit from anti-HER 2 therapy.

A prospective study evaluating the effect of HR status in 3,394 patients with stage I to III HER2+ breast cancer treated in the US National Comprehensive Cancer Network centers demonstrated that patients with HR-/HER2+ disease had a significantly increased hazard of early but 

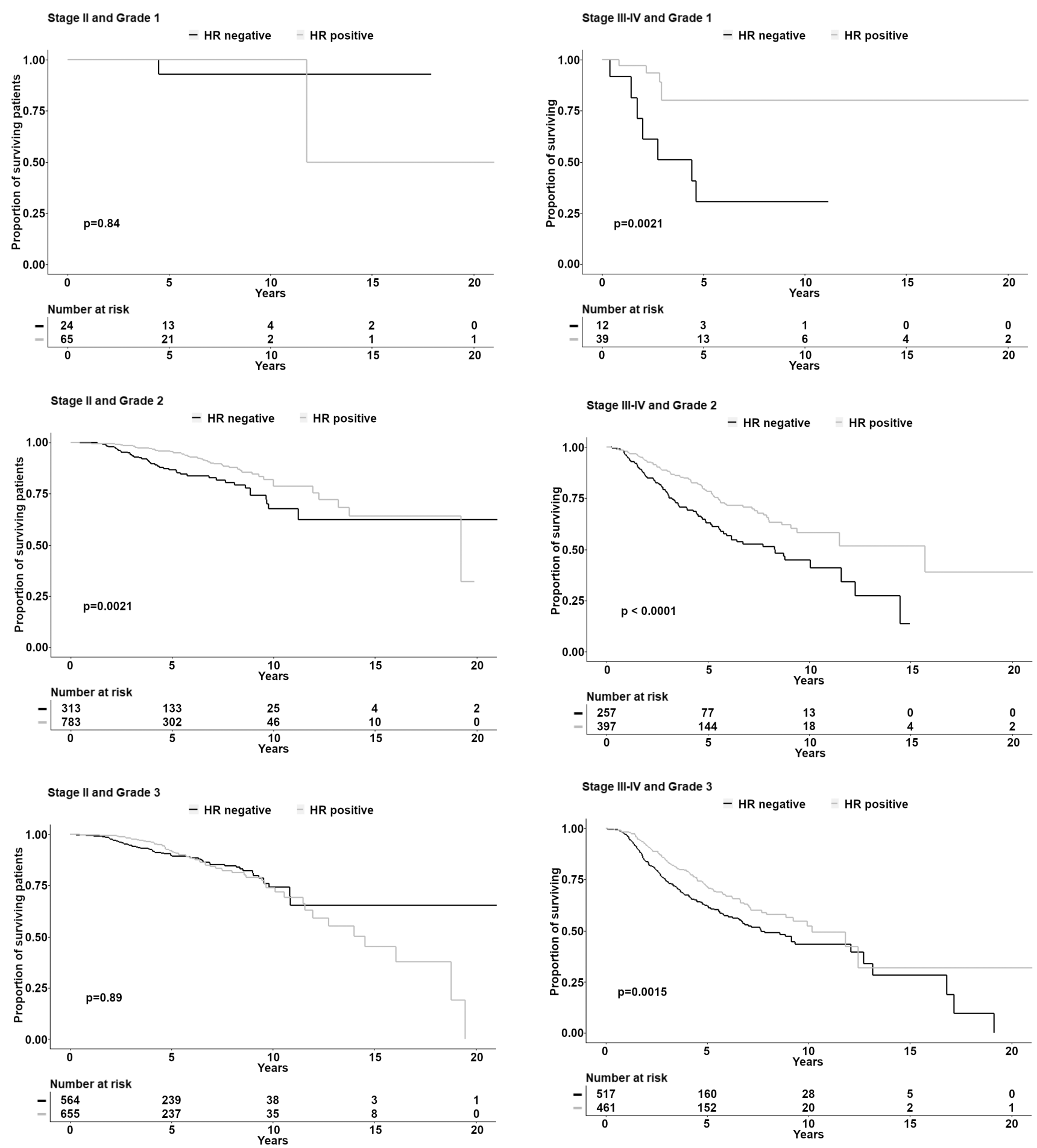

Figure 7. Overall survival according to stage II and grade 1-3.

not late death when compared to TPBC patients These data suggest that the dynamics of relapse rate in TPBC with a high proportion of $\mathrm{HR}+$ cells is similar to relapse curves observed in luminal HR+/HER2-negative breast cancers $[9,26,27]$.

Figure 8. Overall survival according to stage III-IV and grade 1-3.

It cannot be therefore ruled out that some ER+ tumors, particularly those with a high HR positivity, show biological behavior that is similar to that of luminal tumors characterized by a relatively high frequency of late relapses. From the clinical point of view, TPBCs have many specifics that have 
to be taken into consideration in neoadjuvant therapy. In general, ER+ tumor might respond less to cytotoxic therapy. The prognostic significance of pathological complete response after neoadjuvant therapy as a prognostic factor is less reliable in TPBC compared to HER2+/HR- tumors. The pathological complete response has been observed to be achieved less frequently in HER $2+/ \mathrm{HR}+$ tumors, regardless of long-term treatment results [28-30]. In the cohort involved in our study, the OS remained higher in patients with hormone-dependent tumors.

The question is how endocrine, cytotoxic, and anti-HER2 therapies should be optimally used in the management of TPBC in the neoadjuvant setting. Dual inhibition in neoadjuvant therapy is currently being explored. The GeparQuinto trial demonstrated that in patients with HR+ tumors, prolonged anti-HER2 therapy (neoadjuvant lapatinib for 6 months, followed by adjuvant trastuzumab for 12 months) significantly improved OS compared with anti-HER2 therapy with trastuzumab alone. A possible explanation for the benefit observed in TPBC patients in the GeparQuinto study could be the higher risk of late recurrence in these patients as well as the crosstalk of HER2 and hormone receptor signaling, which decreases the efficacy of targeted therapy. Therefore, neoadjuvant therapy with the dual EGFR/ HER2 inhibitor lapatinib, followed by adjuvant therapy with trastuzumab, might result in more effective inhibition of the growth signaling, potentially rendering cells more endocrine responsive, resulting in better survival rates in TPBC patients $[31,32]$.

Only a limited number of studies have investigated the outcomes in advanced/ metastatic TPBC. In the present study, we observed a significantly higher OS in patients with $\mathrm{HR}+/ \mathrm{HER} 2+$ tumors, as compared to patients with hormone independent HER2+ tumors who were diagnosed at stage III and IV. This is in agreement with the study by Howlader et al. [33], which reported the highest survival rates in TPBC patients diagnosed at stage IV even in comparison with $\mathrm{HR}+$ / HER2- breast cancer, which is generally associated with the best prognosis.

The TANDEM, EGF30008, and eLEcTRA trials showed that adding anti-HER2 therapy to endocrine therapy prolongs progression-free survival (PFS) significantly, although the improvement of OS was not statistically significant [34-37].

A combination of anti-HER2 therapy and hormonal agents is therefore considered to represent an acceptable option for postmenopausal patients in whom chemotherapy is considered not feasible. Adding lapatinib to letrozole improves PFS significantly (although at the cost of higher skin toxicity and gastrointestinal toxicity), and adding trastuzumab to anastrozole was proved to prolong PFS [38].

Other retrospective analyses have suggested that adding hormone agents to anti-HER2 therapy and chemotherapy might improve treatment outcomes [39]. This has been translated into the current guidelines by both the American
Society of Clinical Oncology and the European Society for Medical Oncology, which consider adding endocrine therapies to be justified as the maintenance after chemotherapy in TPBC patients in the metastatic setting $[24,40]$.

A number of trials have explored potential approaches to increase the treatment efficacy in TPBC patients. In the PERTAIN trial, addition of pertuzumab to the combination of trastuzumab and aromatase inhibitor after induction chemotherapy given at the investigator discretion in patients with metastatic TPBC resulted in prolongation of median PFS by 3 months [41]. The dual blockade was also investigated in the ALTERNATIVE trial [42] that enrolled patients who had prior treatment with endocrine therapy and disease progression during or after a regimen containing trastuzumab plus chemotherapy in the (neo)adjuvant setting and/ or in the first-line metastatic setting.

The ALTERNATIVE trial reached its primary objective demonstrating improvement in PFS by adding lapatinib to aromatase inhibitor (AI) and trastuzumab compared to AI and trastuzumab alone [38]. The median PFS in the LAP + TRAS + AI arm was 11 months, which is comparable to results of dual inhibition combined with chemotherapy, as observed in the EMILIA or PHEREXA trials [25, 43, 44].

Representativeness of the analyzed dataset represents a strong point of this study. A check of independent sources (i.e. data provided by health insurance companies) proved that this dataset covered almost $100 \%$ of all HER2+ breast cancer patients who were or had been treated in the Czech Republic. Furthermore, information on patient survival was also reliable in the analyzed data because these records had undergone double control; first in hospital information systems, and, subsequently, during the procedure of population-based processing. On the other hand, the present study has limitations in terms of the interpretation because it is a registry-based observational analysis, which cannot aim to replace the matched comparison of arms of a randomized trial. The duration of follow-up is another limitation of the present study: the follow-up period corresponds to the profile of a sample from real clinical practice, and analyses involving follow-up periods longer than 10 years could not be adequately documented, being limited by the achievable sample size. Another important limitation is represented by the reimbursement conditions for targeted therapy that strictly regulate administration of anti-HER2 agents. These restrictions are of particular importance in patients failing trastuzumab therapy and limit the use of anti-HER2 drugs with other agents.

In conclusion, results of the present study indicate that patients with $\mathrm{HER} 2+/ \mathrm{HR}+$ tumors, as compared to patients with HER2+/HR- tumors, tend to present at an earlier disease stage, with lower tumor grades and are more frequently premenopausal at the time of diagnosis. In the first five years after diagnosis, the OS is significantly higher in all subgroups of $\mathrm{HR}+$ patients classified by treatment setting, i.e. those treated with neoadjuvant, adjuvant, and 
palliative therapy. When evaluated by stages, significantly higher OS was observed in HR+ patients diagnosed at stages II, III, and IV. We can conclude that we found an OS benefit in patients with HER2+ and HR+ tumors when compared to patients with HER2+ and HR- tumors. This difference was partly caused by differences in the presence of prognostic parameters in both groups, partly obviously by differences in their biological behavior. Although the results of our study are limited by common biases, which are caused by the design of a non-interventional database focused on the collection of epidemiological and clinical data, we consider the differences in the overall survival of both groups to be significant.

Trastuzumab became the first therapy targeting HER2. The unprecedented success of trastuzumab paved the way for the introduction of other HER2 targeted therapies, including other monoclonal antibodies (pertuzumab), dual tyrosine kinase inhibitors (lapatinib and neratinib), and antibody conjugates (e.g. trastuzumabemtansine or TDM-1). The medical therapy of HER2-positive breast cancer is mostly based on concomitant or sequential combinations of HER2-targeting agents with cytotoxic or hormonal drugs.

Mutual interactions between HER2 and hormone receptor pathways in TPBC resulted in a lot of ambiguity, and the optimal utilization of chemotherapy, hormonal treatment, and anti-HER2 therapy in treatment management has yet to be defined. According to guidelines currently used in the Czech Republic, anti-HER2 therapy should be continued after the failure of first-line treatment. In patients with HR+ tumors, after the initial anti-HER2 treatment with chemotherapy, when the response is achieved, the maintenance therapy can be continued as a combination of anti-HER2 treatment and endocrine therapy.

Acknowledgments: We would like to thank the following heads of comprehensive cancer centers for their permission to use data on patients from their respective regional networks: Rostislav Vyzula (Masaryk Memorial Cancer Institute, Brno), Luboš Petruželka (General University Hospital, Prague), Bohuslav Melichar (University Hospital, Olomouc), David Vrana (Hospital Novy Jicin), Jiri Petera (University Hospital Hradec Kralove), Jana Prausova (University Hospital in Motol, Prague), Jindrich Finek (University Hospital Plzen), Vaclav Janovsky (Hospital Ceske Budejovice), Jaroslav Vanasek (Multiscan and Hospital Pardubice), Jiri Bartos (Regional Hospital Liberec), Jakub Cvek (University Hospital Ostrava), Tomas Büchler (Thomayer Hospital, Prague), Lubomir Slavicek (Hospital Jihlava), Martina Chodacka (Masaryk Hospital Usti nad Labem and Hospital Chomutov), Milan Kohoutek (Tomas Bata Regional Hospital, Zlin), Jiri Mayer (University Hospital, Brno), Renata Soumarova (University Hospital Kralovske Vinohrady, Prague), Lubos Petruzelka (Hospital Na Bulovce, Prague), Martin Safanda (Hospital Na Homolce, Prague), Jana Katolicka (St. Anne's University Hospital, Brno). We are also indebted to all physicians who entered data into the database.

\section{References}

[1] EARLY BREAST CANCER TRIALISTS' COLLABORATIVE GROUP (EBCTCG), PETO R, DAVIES C, GODWIN J, GRAY R et al. Comparisons between different polychemotherapy regimens for early breast cancer: meta-analyses of long-term outcome among 100,000 women in 123 randomised trials. Lancet 2012; 379: 432-444. https://doi. org/10.1016/S0140-6736(11)61625-5

[2] EARLY BREAST CANCER TRIALISTS' COLLABORATIVE GROUP (EBCTCG), DAVIES C, GODWIN J, GRAY $\mathrm{R}$, CLARKE $\mathrm{M}$ et al. Relevance of breast cancer hormone receptors and other factors to the efficacy of adjuvant tamoxifen: patient-level meta-analysis of randomised trials. Lancet 2011; 378: 771-784. https://doi.org/10.1016/S01406736(11)60993-8

[3] EARLY BREAST CANCER TRIALISTS' COLLABORATIVE GROUP (EBCTCG), DARBY S, MCGALE P, CORREA C, TAYLOR C et al. Effect of radiotherapy after breastconserving surgery on 10-year recurrence and 15-year breast cancer death: meta-analysis of individual patient data for 10,801 women in 17 randomised trials. Lancet 2011; 378: 1707-1716. https://doi.org/10.1016/S0140-6736(11)61629-2

[4] MELICHAR B. Laboratory medicine and medical oncology: the tale of two Cinderellas. Clin Chem Lab Med 2013; 51: 99-112. https://doi.org/10.1515/cclm-2012-0496

[5] HARVEY JM, CLARK GM, OSBORNE CK, ALLRED DC. Estrogen receptor status by immunohistochemistry is superior to the ligand-binding assay for predicting response to adjuvant endocrine therapy in breast cancer. J Clin Oncol 1999; 17: 1474-1481. https://doi.org/10.1200/JCO.1999.17.5.1474

[6] PERTSCHUK LP, KIM DS, NAYER K, FELDMAN JG, EISENBERG $\mathrm{KB}$ et al. Immunocytochemical estrogen and progestin receptor assays in breast cancer with monoclonal antibodies. Histopathologic, demographic, and biochemical correlations and relationship to endocrine response and survival. Cancer 1990; 66: 1663-1670. https:// doi.org/10.1002/1097-0142(19901015)66:8<1663::aidcncr2820660802>3.0.co;2-c

[7] BARTLETT JM, BROOKES CL, ROBSON T, VAN DE VELDE CJ, BILLINGHAM LJ et al. Estrogen receptor and progesterone receptor as predictive biomarkers of response to endocrine therapy: a prospectively powered pathology study in the Tamoxifen and Exemestane Adjuvant Multinational trial. J Clin Oncol 2011; 29: 1531-1538. https://doi. org/10.1200/JCO.2010.30.3677

[8] COLZANI E, LILJEGREN A, JOHANSSON AL, ADOLFSSON J, HELLBORG $\mathrm{H}$ et al. Prognosis of patients with breast cancer: causes of death and effects of time since diagnosis, age, and tumor characteristics. J Clin Oncol 2011; 29: 40144021. https://doi.org/10.1200/JCO.2010.32.6462

[9] COLLEONI M, SUN Z, PRICE KN, KARLSSON P, FORBES JF et al. Annual Hazard Rates of Recurrence for Breast Cancer During 24 Years of Follow-Up: Results From the International Breast Cancer Study Group Trials I to V. J Clin Oncol 2016; 34: 927-935. https://doi.org/10.1200/ JCO.2015.62.3504 
[10] TANDON AK, CLARK GM, CHAMNESS GC, ULLRICH A, MCGUIRE WL. HER-2/neu oncogene protein and prognosis in breast cancer. J Clin Oncol 1989; 7: 1120-1128. https://doi.org/10.1200/JCO.1989.7.8.1120

[11] GUSTERSON BA, GELBER RD, GOLDHIRSCH A, PRICE KN, SÄVE-SÖDERBORGH J et al. Prognostic importance of c-erbB-2 expression in breast cancer. International (Ludwig) Breast Cancer Study Group. J Clin Oncol 1992; 10: 1049-1056. https://doi.org/10.1200/JCO.1992.10.7.1049

[12] CHIA S, NORRIS B, SPEERS C, CHEANG M, GILKS B et al. Human epidermal growth factor receptor 2 overexpression as a prognostic factor in a large tissue microarray series of node-negative breast cancers. J Clin Oncol 2008; 26: 5697-5704. https://doi.org/10.1200/JCO.2007.15.8659

[13] WU VS, KANAYA N, LO C MORTIMER J, CHEN S. From bench to bedside: what do we know about hormone receptor-positive and human epidermal growth factor receptor 2-positive breast cancer? J Steroid Biochem Mol Biol 2015; 153: 45-53. https://doi.org/10.1016/j.jsbmb.2015.05.005

[14] PRAT A, BASELGA J. The role of hormonal therapy in the management of hormonal-receptor-positive breast cancer with co-expression of HER2. Nat Clin Pract Oncol 2008; 5: 531-542. https://doi.org/10.1038/ncponc1179

[15] LOUSBERG L, COLLIGNON J, JERUSALEM G. Resistance to therapy in estrogen receptor positive and human epidermal growth factor 2 positive breast cancers: progress with latest therapeutic strategies. Ther Adv Med Oncol 2016; 8: 429-449. https://doi.org/10.1177/1758834016665077

[16] OSBORNE CK, SCHIFF R. Mechanisms of endocrine resistance in breast cancer. Annu Rev Med 2011; 62: 233-247. https://doi.org/10.1146/annurev-med-070909-182917

[17] LAL P, TAN LK, CHEN B. Correlation of HER-2 status with estrogen and progesterone receptors and histologic features in 3655 invasive breast carcinomas. Am J Clin Pathol 2005; 123: 541-546. https://doi.org/10.1309/YMJ3-A83T-B39MRUT9

[18] COLLINS D, JACOB W, CEJALVO JM,CEPPI M, JAMES I et al. Direct estrogen receptor (ER)/HER family crosstalk mediating sensitivity to lumretuzumab and pertuzumab in ER+ breast cancer. PLoS One 2017; 12: e0177331. https://doi. org/10.1371/journal.pone.0177331

[19] WANG YC, MORRISON G, GILLIHAN R,GUO J, WARD RM et al. Different mechanisms for resistance to trastuzumab versus lapatinib in HER2-positive breast cancers - role of estrogen receptor and HER2 reactivation. Breast Cancer Res 2011; 13: R121. https://doi.org/10.1186/bcr3067

[20] GIULIANO M, HU H, WANG YC, FU X, NARDONE A et al. Upregulation of ER signaling as an adaptive mechanism of cell survival in HER2-positive breast tumors treated with anti-HER2 therapy. Clin Cancer Res 2015; 21: 3995-4003. https://doi.org/10.1158/1078-0432.CCR-14-2728

[21] GIULIANO M, TRIVEDI MV, SCHIFF R. Bidirectional crosstalk between the estrogen receptor and human epidermal growth factor receptor 2 signaling pathways in breast cancer: molecular basis and clinical implications. Breast Care (Basel) 2013; 8: 256-262. https://doi.org/10.1159/000354253
[22] VICI P, PIZZUTI L, SPERDUTI I, FRASSOLDATI A, NATOLI C et al. "Triple positive" early breast cancer: an observational multicenter retrospective analysis of outcome. Oncotarget 2016; 7: 17932-17944. https://doi.org/10.18632/ oncotarget. 7480

[23] NCCN. Breast Cancer Guidelines, Ver. 1.2018. (2018). Available from: www.nccn.org (Accessed: March 20, 2018).

[24] GIORDANO SH, TEMIN S, KIRSHNER JJ, CHANDARLAPATY S, CREWS JR et al. Systemic therapy for patients with advanced human epidermal growth factor receptor 2-positive breast cancer: American society of clinical oncology clinical practice guideline. J Clin Oncol 2014; 32: 2078 2099. https://doi.org/10.1200/JCO.2013.54.0948

[25] LARIONOV AA. Current Therapies for Human Epidermal Growth Factor Receptor 2-Positive Metastatic Breast Cancer Patients. Front Oncol 2018; 8: 89. https://doi.org/10.3389/ fonc.2018.00089

[26] CHUMSRI S, LI Z, SERIE DJ, MASHADI-HOSSEIN A, COLON-OTERO G et al. Incidence of Late Relapses in Patients With HER2-Positive Breast Cancer Receiving Adjuvant Trastuzumab: Combined Analysis of NCCTG N9831 (Alliance) and NRG Oncology/NSABP B-31. J Clin Oncol 2019; 37: 3425-3435. https://doi.org/10.1200/JCO.19.00443

[27] VAZ-LUIS I, OTTESEN RA, HUGHES ME, MARCOM PK, MOY B et al. Impact of hormone receptor status on patterns of recurrence and clinical outcomes among patients with human epidermal growth factor-2-positive breast cancer in the National Comprehensive Cancer Network: a prospective cohort study. Breast Cancer Res 2012; 14: R129. https://doi. org/10.1186/bcr3324

[28] VICI P, PIZZUTI L, NATOLI C, GAMUCCI T, DI LAURO L et al. Triple positive breast cancer: a distinct subtype? Cancer Treat Rev 2015; 41: 69-76. https://doi.org/10.1016/j. ctrv.2014.12.005

[29] EARLY BREAST CANCER TRIALISTS' COLLABORATIVE GROUP (EBCTCG). Effects of chemotherapy and hormonal therapy for early breast cancer on recurrence and 15-year survival: an overview of the randomised trials. Lancet 2005; 365: 1687-1717. https://doi.org/10.1016/S01406736(05)66544-0.

[30] BERRY DA, CIRRINCIONE C, HENDERSON IC,CITRON ML, BUDMAN DR et al. Estrogen-receptor status and outcomes of modern chemotherapy for patients with node-positive breast cancer. JAMA 2006; 295: 1658-1667. https://doi. org/10.1001/jama.295.14.1658

[31] UNTCH M, VON MINCKWITZ G, GERBER B, SCHEM C, REZAI M et al. Survival Analysis After Neoadjuvant Chemotherapy With Trastuzumab or Lapatinib in Patients With Human Epidermal Growth Factor Receptor 2-Positive Breast Cancer in the GeparQuinto (G5) Study (GBG 44). J Clin Oncol 2018; 36: 1308-1316. https://doi.org/10.1200/ JCO.2017.75.9175

[32] NAHTA R, O'REGAN RM. Therapeutic implications of estrogen receptor signaling in HER2-positive breast cancers. Breast Cancer Res Treat 2012; 135: 39-48. https://doi. org/10.1007/s10549-012-2067-8 
[33] HOWLADER N, CRONIN KA, KURIAN AW, ANDRIDGE R. Differences in breast cancer survival by molecular subtypes in the United States. Cancer Epidemiol Biomarkers Prev 2018; 27: 619-626. https://doi.org/10.1158/1055-9965. EPI-17-0627

[34] KAUFMAN B, MACKEY JR, CLEMENS MR, BAPSY PP, VAID A et al. Trastuzumab plus anastrozole versus anastrozole alone for the treatment of postmenopausal women with human epidermal growth factor receptor 2-positive, hormone receptor-positive metastatic breast cancer: results from the randomized phase III TAnDEM study. J Clin Oncol 2009; 27: 5529-5537. https://doi.org/10.1200/JCO.2008.20.6847

[35] JOHNSTON S, PIPPEN J JR, PIVOT X, LICHINITSER M, SADEGHI $S$ et al. Lapatinib combined with letrozole versus letrozole and placebo as first-line therapy for postmenopausal hormone receptor-positive metastatic breast cancer. J Clin Oncol 2009; 27: 5538-5546. https://doi.org/10.1200/ JCO.2009.23.3734

[36] SCHWARTZBERG LS, FRANCO SX, FLORANCE A, O'ROURKE L, MALTZMAN J et al. Lapatinib plus letrozole as first-line therapy for HER-2+ hormone receptor-positive metastatic breast cancer. Oncologist 2010; 15: 122-129. https://doi.org/10.1634/theoncologist.2009-0240

[37] HUOBER J, FASCHING PA, BARSOUM M, PETRUZELKA L, WALLWIENER D et al. Higher efficacy of letrozole in combination with trastuzumab compared to letrozole monotherapy as first-line treatment in patients with HER2positive, hormone-receptor-positive metastatic breast cancer - results of the eLEcTRA trial. Breast 2012; 21: 27-33. https://doi.org/10.1016/j.breast.2011.07.006

[38] SEIDMAN AD, BORDELEAU L, FEHRENBACHER L, BARLOW WE, PERLMUTTER J et al. National Cancer Institute Breast Cancer Steering Committee Working Group Report on Meaningful and Appropriate End Points for Clinical Trials in Metastatic Breast Cancer. J Clin Oncol 2018; 36 : 3259-3268. https://doi.org/10.1200/JCO.18.00242
[39] HAYASHI N, NIIKURA N, YAMAUCHI H, NAKAMURA $S$, UENO NT et al. Adding hormonal therapy to chemotherapy and trastuzumab improves prognosis in patients with hormone receptor-positive and human epidermal growth factor receptor 2-positive primary breast cancer. Breast Cancer Res Treat 2013; 137: 523-531. https://doi.org/10.1007/ s10549-012-2336-6

[40] CARDOSO F, COSTA A, SENKUS E, AAPRO M, ANDRÉ $F$ et al. 3rd ESO-ESMO international consensus guidelines for advanced breast cancer (ABC 3). Ann Oncol 2017; 28: 16-33. https://doi.org/10.1093/annonc/mdw544

[41] ARPINO G, FERRERO JM, DE LA HABA-RODRIGUEZ J, EASTON V, SCHUHMACHER C et al. Primary analysis of PERTAIN: a randomized, two-arm, open-label, multicenter phase II trial assessing the efficacy and safety of pertuzumab given in combination with trastuzumab plus an aromatase inhibitor in first-line patients with HER2-positive and hormone receptor-positive metastatic or locally advanced breast cancer. Cancer Res 2017; 77: S3-04. https://doi. org/10.1158/1538-7445.SABCS16-S3-04

[42] GRADISHAR WJ, HEGG R, IM S, PARK IH, TJULANDIN $S$ et al. Phase III study of lapatinib (L) plus trastuzumab (T) and aromatase inhibitor (AI) vs $\mathrm{T}+\mathrm{AI}$ vs $\mathrm{L}+\mathrm{AI}$ in postmenopausal women (PMW) with HER2+, HR+ metastatic breast cancer (MBC): ALTERNATIVE. Journal of Clinical Oncology 2017; 35: 1004-1004. https://doi.org/10.1200/ JCO.2017.35.15_suppl.1004

[43] VERMA S, MILES D, GIANNI L, KROP IE, WELSLAU M et al. Trastuzumabemtansine for HER2-positive advanced breast cancer. N Engl J Med 2012; 367: 1783-1791. https:// doi.org/10.1056/NEJMoa1209124

[44] URRUTICOECHEA A, RIZWANULLAH M, IM SA, RUIZ ACS, LÁNG I et al. Randomized phase III trial of trastuzumab plus capecitabine with or without pertuzumab in patients with human epidermal growth factor receptor 2-positive metastatic breast cancer who experienced disease progression during or after trastuzumab-based therapy. J Clin Oncol 2017; 35: 3030-3038. https://doi.org/10.1200/ JCO.2016.70.6267 